\title{
Systematic Thinking Underlying People with Diabetes' Beliefs on Health Outcomes: An Information Integration Theory Approach
}

\author{
Perla Lizeth Hernández-Cortés ${ }^{1}$, Guadalupe Elizabeth Morales Martínes², \\ López Ramírez Ernesto Octavio ${ }^{2}$, Bertha Cecilia Salazar-González ${ }^{1}$ \\ ${ }^{1}$ School of Nursing, Universidad Autonoma de Nuevo Leon, San Nicolás de los Garza, Mexico \\ ${ }^{2}$ Department of Psychology, Universidad Autonoma de Nuevo León, San Nicolás de los Garza, Mexico \\ Email: elopez42@att.net.mx
}

Received 1 July 2014; revised 7 August 2014; accepted 3 September 2014

Copyright (C) 2014 by authors and Scientific Research Publishing Inc.

This work is licensed under the Creative Commons Attribution International License (CC BY). http://creativecommons.org/licenses/by/4.0/

c) (i) Open Access

\section{Abstract}

A sample of 76 older adults (27 with diabetes and 49 without diabetes) were selected to judge three information factors, metamemory related to-drug organization-stress and physical activity in relation to their perception of self-care. In order to do so, an Integration Information Theory was considered to determine systematic cognitive algebra rules underlying judgment about 24 different health self-care scenarios. Results indicate that older adults without diabetes use a summative cognitive rule to integrate relevant health information but older adults with diabetes do not. Both groups agreed that metamemory was the most relevant factor to their self-care followed by stress and physical activity. However, valuation of these factors does depend on the type of group. Implications of these results to healthcare a behavioral nursing intervention are discussed in this paper.

\section{Keywords}

Diabetes, Health Prediction Models, Information Integration Theories (IIT), Functional Measurement

\section{Introduction}

Psychological determinants of health behaviors have been a major concern of relevant cognitive theories of health like the Theory of Planned Behavior (TPB), Health Belief Model (HBM), and Protection Motivation Theory (PMT). Overall, these models suggest that thoughts and feelings a person has regarding a healthy beha- 
vior predict if this he/she will perform that behavior [1].

Take the TPB model for instance which has shown appropriate prediction of a wide range of health behaviors [2]. Specifically, this model assumes that intention is the best predictor of behavior. Intention in turn is determined by attitudes, subjective norms, and perceived behavioral control [3]. Here, attitudes are understood as emotion-valenced evaluations of behavior, while subjective norms are considered to be perceptions of how other people will react if a specific behavior is carried on. Finally, it studies the perceived behavioral control measures, the perceived degree of control or confidence the individual has over performing the behavior.

In spite of the tremendous influence of TPB and its related Theory of Reasoned Action (TRA; [3]) on health issues [4], there is academic evidence suggesting that TPB's capacity to predict behavior is overstated. For example, Jaccard and Becker [5] showed that markedly superior predictive power is obtained from attitude decision models when they are compared to TPB in real life situations (see also [6]). Alternatively, instances of decision models extend their capacity to account not only for attitudes mean values of a group of people but allow tapping into subjective norms within the value system of each individual and other nonattitudinal determinants relevant to health behavior. Under this rationale let us consider next the theory and practical benefits of introducing an Integration Information Theory (IIT [7]) decision model to approach heath issues related to self-care behavior in persons with diabetes.

\subsection{Functional Measurement IIT and Algebraic Ruled Health Behavior}

In keeping with TPB's assumption about the relevance of attitude formation to intention and prediction of behavior, let us consider a comparison between this model and an IIT approach. At the heart of TPB/TRA models there is an expectancy-value model characterizing systematic thinking underlying health behavior [8]. Here, an attitude is formed by summing the multiplicative combination of: 1) the strength of a salient belief that a behavior will produce a given outcome and 2) the subjective evaluation of this outcome, such that:

$$
\text { Attitude }=\sum b_{i} e_{i},
$$

where $b_{i}$ represents the strength of the belief and $e_{i}$ is the value of the attitude object on attribute $i$ evaluation. Beliefs and evaluations are typically scored on 7-point scales. In this model it is assumed that by multiplying the expectancy and value components associated with each outcome and summing up these products determines an attitude. This model implies deliberative processing since it involves the analysis of available information and an analysis of positive and negative attributes of the attitude object as well as consideration of weighted costs and benefits of engaging in a particular course of action.

The Fishbein-Ajzen model is meritorious in itself due to its strong emphasis on predicting every day specific behaviors. Even though two main concerns emerge from this way to approach cognitive based intention. First, this model is related to attitudes, neither to beliefs nor value formal specification. On the other hand, alternative belief models like the Health Belief Model (HBM; for a review see [9]) does not do well on specifying this cognitive concepts. Specifically, the HBM model assumes that a person's perception (beliefs) of a threat derived from a health problem and the evaluation of actions aimed at reducing such a threat, promotes health-seeking behavior. However, the HBM model (the same for TPB) is more oriented to determine behavior prediction rather than to specify cognitive processing of beliefs and cognitive valuation of events. As suggested by Anderson [7] (p: 128): "These two directions, namely, prediction of behavioral outcomes and understanding of cognitive processes, impose generally different constraints on strategy and tactics of investigation. Hence they usually interfere with each other...”. On the other hand, lack of cognitive specification of beliefs and valuation of events may limit prediction power of adherence to healthy behavior. This is the case for HBM research where reported problems of scale reliability and validity due to multicollinearity of research variables raise doubts about measured concepts [10].

Thus, no doubt that more cognitive specification about beliefs and valuation is needed to understand why people's choices relate to certain health outcomes. This cognitive research goal can be achieved by considering an IIT approach. The IIT postulates that relevant stimuli $\left(\mathrm{S}_{\mathrm{i}}\right)$ are extracted from an environment and psychologically represented through a valuation process $(\mathrm{V})$ with cognitive coefficients $\left(\psi_{\mathrm{i}}\right)$. Here, a person is assumed to combine these subjective values (I) by means of a cognitive algebra dominated by addition, multiplication, and averaging to form a unified implicit response $(\rho)$ that will produce an explicit response (R) through an action operator (A). This goal oriented and feed forward cognitive processing is best represented by the IIT functional 
diagram in Figure 1.

Whilst valuation (V) of information depends on each individual's perception of events, the integration (I) relates to generalizable systematic cognitive processing across a sample of individuals. This cognitive algebraic behavior can be specified by IIT functional measurement methodology (FMIIT) as described in the current article's method section. This is relevant because cognitive specification of systematic thinking deepens our knowledge about people's beliefs. For instance, there is robust evidence suggesting that people tend to follow an average integration rule to attitude formation and change rather than a summatory of products like in the Fishbein and Ajzen's expectancy-value model [7] [12]. Furthermore, in contrast to TBP, the IIT model allows to study much broader concepts regarding either attitudes toward targets or behavior [13].

Regarding diabetes mellitus, no cognitive algebra specification research exists. Again, this is so, since TPB/ TRA, PMT and HBM approaches on this topic focus on prediction rather than on understanding.

Thus, the study discussed in this paper aims at understanding how specific pieces of information affecting a diabetic illness condition are cognitively processed by old people having this condition. In doing so, we adopted the principles of IIT. However, the main interest is to explore health cognitions based on systematic thinking (e.g. summatory/multiplicative rules) rather than to explore attitude formation or predicting behavior.

\subsection{IIT and Perceived Health Threats Due to Diabetes and Cognitive Deficits during the Third Age}

More than often patients with diabetes are required to carry out self-care behaviors like dietary change, exercise, medication, self-monitoring of blood glucose (SMBG), and regular attendance at clinic for health monitoring. It is clear, however, that patients with diabetes tend to care less about their illness than health care professionals [14]. This might be related to the fact that diabetes, at least prior to the development of advanced complications, is mostly an asymptomatic condition. Rather, patients with a diabetic condition seem to rely on health beliefs, illness representations (IRs) or personal models [15]. However, according to HBM research, perceived illness severity and vulnerability is associated with regimen adherence [16]. Extension to these academic observations suggest that factors that seem to intervene in positive health outcomes relate to complexity of self-management of medication (Cognitive control [17]), and perceived self-efficacy [18] [19]. Perceived vulnerability can be related to aging, especially during third age where cognitive decline seems to increase. However, there is still ambiguous evidence about if self-care behavior may be influenced by cognitive decline function. This is so since it is not clear if diabetes indeed relates to cognitive decline [20], or not [21]. This ambiguity seems to disappear if instead of considering cross-sectional research approach, a longitudinal research approach is considered. Longitudinal studies have clearly demonstrated that diabetes mellitus is associated with increased rate of cognitive decline or an increased incidence of dementia [22] [23]. Moreover, if only type II diabetes is considered then is clear that either by considering cross-sectional [21] [24] or longitudinal data a strong positive relation is obtained between diabetes and cognitive decline.

The current study aims to determine if perceived cognitive decline in the third age affects persons' without and with diabetes's, judgment about self-care capacity. In doing so, we considered the possibility that observed memory deficits (e.g. perceived low metamemory capacity) are judged relevant to self-management health care in old people with diabetes (documented memory deficits vs. diabetes [25]. Regarding this judgment, relevant



Figure 1. The integration information theory diagram [11]. 
cognitive factors in the third age like emotional states (due to stress [26]) and physical activity were considered.

Our main hypotheses for this study assumes that third age memory ailments (like reduced metamemory capacity) are judged differently relevant to self-care depending if an older adult is under different stress levels, has an illness like diabetes and carry over exercise routines. To learn which concepts are more relevant to older adults with diabetes in comparison to older adults who do not have this condition may guide nurses to develop interventions focusing on the importance of activities related to concepts given less weight by them. Systematic thinking of all participants about these factors should reveal at least summatory or multiplicative rules where valuation to each factor could depend on their health condition.

\section{Method}

\subsection{Participants}

This study considered a sample of 76 older adults (27 with diabetes and 49 without diabetes) from a Northern City of Mexico voluntarily agreed to participate in this study. Their age interval varied between 61 and 80 years old $($ Mean $=68.93$; $\mathrm{SD}=3.71)$. Older adults who manifested having Diabetes (11 women and 8 men) said they had have this physical condition for more than 10 years (Mean $=11.19$, SD $=8.42$ ). Institutional as well as ethical committee consent was obtained before recruiting participants (from 10 Mexican government institutions where older adults gather for different purposes like leisure activities, learning or exercising).

\subsection{Instruments}

Twenty four scenarios were created describing self-care behavior for an older adult having diabetes. An IIT cognitive algebra design was used to build these vignettes where three sources of information were considered as independent variables: Cognitive condition (low, medium and high metamemory capacity), stress condition (relaxed, stressed) and physical activity (sedentary, active). At the end of each scenario, a question was presented asking each participant how likely it was that the described scenario actor's health was at risk. Then a 10-point scale ranged was introduced. This scale was left anchored with a label "Not risk at all" and right anchored "Completely at risk":

"Estela is a 60 year old lady. She is rather a sedentary person who has no physical activity and she does not worry too much about things, she is a relaxed person. Estela has diabetes, but she is very well organized about her medication schedule. She never forgets to take on time her medicine.”

By considering the above scenario, to what extent do you think Estela's health is at risk?

No risk at allo------0-----0-----0-----0------0-----0-----0-----0-----0-----o Completely at risk.

Each source of information is orthogonally combined with a gender factor to obtain a global factor design 2 (Gender) $\times 2$ (Stress) $\times 2$ (Physical activity) $\times 3$ (Metamemory)

\subsection{Procedure}

Participants were tested individually; they were required to read each of the 24 scenarios and rate each one, on a 10 -point scale, the probability of a person being at health risk. Scenarios were randomly presented on printed paper cards (vignettes). The required time to complete the study takes around 60 minutes.

\section{Results}

Having in mind that neither significant main effects were obtained for level of education $(F(1,67)=2.47, p=$ $\left.0.12, \eta_{p}^{2}=0.03\right)$ and gender $\left(F(1,67)=0.008, p=0.92, \eta_{p}^{2}=0.0001\right.$ ), a global mixed ANOVA 2 (without vs. with diabetes) $\times 2 \times 2 \times 2 \times 3$ was carried out. Table 1 shows results of this statistical analysis.

Notice from Table 1 that metamemory had the highest effect to both groups followed by stress and Physical activity. That is, cognitive deficits are most relevant to health self-care (even more than physical activity or medication). A cognitive algebra analysis of data pattern results for metamemory can be obtained from Figure 2.

A quick look to Figure 2 shows that factor order relevance is the same to both groups (metamemory, stress and physical activity) but valuation (risk perception) of factors was different depending on the group (see Table 2). This valuation differences are relevant even when only a marginal main significant effect is obtained for diagnosis (Diabetes/No Diabetes). First, notice the data pattern presented by older adults without diabetes. This 
Table 1. General ANOVA.

\begin{tabular}{|c|c|c|c|c|c|c|c|}
\hline Source & Df & MS & df & MS & $\mathrm{F}$ & $p$ & $\eta^{2}$ \\
\hline \multicolumn{8}{|c|}{$(\mathrm{N}=76)(\mathrm{M}=6)$} \\
\hline Diabetes condition (D) & 1 & 98.62 & 73 & 28.16 & 3.50 & 0.065 & 0.047 \\
\hline Gender (G) & 1 & 0.00006 & 73 & 2.61 & 0.61 & 0.996 & 0.000 \\
\hline Physical activity (PA) & 1 & 329.53 & 73 & 8.90 & 37.00 & 0.000 & 0.336 \\
\hline Stress (S) & 1 & 726.44 & 73 & 11.08 & 65.52 & 0.000 & 0.473 \\
\hline Metamemory (M) & 2 & 2954.39 & 146 & 17.106 & 172.70 & 0.000 & 0.70 \\
\hline $\mathrm{G} * \mathrm{D}$ & 1 & 1.60 & 73 & 2.61 & 0.61 & 0.437 & 0.008 \\
\hline $\mathrm{PA} * \mathrm{D}$ & 1 & 0.68 & 73 & 8.904 & 0.07 & 0.781 & 0.001 \\
\hline $\mathrm{S} * \mathrm{D}$ & 1 & 8.06 & 73 & 11.08 & 0.72 & 0.396 & 0.009 \\
\hline $\mathrm{M} * \mathrm{D}$ & 2 & 16.19 & 146 & 17.10 & 0.94 & 0.390 & 0.012 \\
\hline $\mathrm{G} * \mathrm{PA}$ & 1 & 0.88 & 73 & 3.06 & 0.28 & 0.593 & 0.003 \\
\hline $\mathrm{G} * \mathrm{~S}$ & 1 & 5.50 & 73 & 4.04 & 1.36 & 0.247 & 0.018 \\
\hline $\mathrm{PA} * \mathrm{~S}$ & 1 & 6.844 & 73 & 3.655 & 1.872 & 0.175 & 0.025 \\
\hline $\mathrm{G} * \mathrm{M}$ & 1 & 7.32 & 146 & 3.18 & 2.30 & 0.103 & 0.030 \\
\hline $\mathrm{PA} * \mathrm{M}$ & 2 & 8.40 & 146 & 3.78 & 2.21 & 0.112 & 0.029 \\
\hline $\mathrm{S} * \mathrm{M}$ & 2 & 21.70 & 146 & 3.90 & 5.55 & 0.004 & 0.07 \\
\hline
\end{tabular}

Table 2. ANOVA for each group.

\begin{tabular}{|c|c|c|c|c|c|c|c|}
\hline Source & $\mathrm{df}$ & MS & $\mathrm{df}$ & MS & $\mathrm{F}$ & $p$ & $\eta^{2}$ \\
\hline \multicolumn{8}{|c|}{ "Without diabetes $(\mathrm{N}=49)(\mathrm{M}=6.0) "$} \\
\hline Gender (G) & 1 & 1.12 & 47 & 2.87 & 0.39 & 0.53 & 0.008 \\
\hline Physical activity (PA) & 1 & 208.42 & 47 & 8.62 & 24.15 & 0.000 & 0.339 \\
\hline Stress (E) & 1 & 403.75 & 47 & 11.78 & 34.24 & 0.000 & 0.421 \\
\hline Metamemory (M) & 2 & 1840.13 & 94 & 16.06 & 114.50 & 0.000 & 0.708 \\
\hline $\mathrm{G} * \mathrm{PA}$ & 1 & 5.28 & 47 & 5.28 & 2.01 & 0.162 & 0.041 \\
\hline $\mathrm{G} * \mathrm{~S}$ & 1 & 2.920 & 47 & 3.20 & 0.91 & 0.344 & 0.019 \\
\hline $\mathrm{PA} * \mathrm{~S}$ & 1 & 6.12 & 47 & 3.32 & 1.844 & 0.180 & 0.037 \\
\hline $\mathrm{G} * \mathrm{M}$ & 2 & 1.54 & 94 & 3.38 & 0.45 & 0.635 & 0.009 \\
\hline $\mathrm{A} * \mathrm{M}$ & 2 & 6.81 & 94 & 3.04 & 2.24 & 0.111 & 0.045 \\
\hline $\mathrm{S} * \mathrm{M}$ & 2 & 17.85 & 94 & 3.38 & 5.27 & 0.006 & 0.100 \\
\hline \multicolumn{8}{|c|}{ "With diabetes $(\mathrm{N}=27)(\mathrm{M}=6.4) "$} \\
\hline Gender (G) & 1 & 0.61 & 26 & 2.16 & 0.28 & 0.597 & 0.010 \\
\hline Physical activity (PA) & 1 & 140.74 & 26 & 9.40 & 14.97 & 0.000 & 0.365 \\
\hline Ssress (S) & 1 & 346.72 & 26 & 9.81 & 35.31 & 0.000 & 0.575 \\
\hline Metamemory (M) & 2 & 1285.69 & 52 & 18.97 & 67.74 & 0.000 & 0.722 \\
\hline $\mathrm{G} * \mathrm{PA}$ & 1 & 0.30 & 26 & 3.87 & 0.07 & 0.782 & 0.002 \\
\hline $\mathrm{G} * \mathrm{~S}$ & 1 & 2.72 & 26 & 5.56 & 0.48 & 0.490 & 0.018 \\
\hline $\mathrm{PA} * \mathrm{~S}$ & 1 & 1.99 & 26 & 4.26 & 0.46 & 0.499 & 0.017 \\
\hline $\mathrm{G} * \mathrm{M}$ & 2 & 10.89 & 52 & 2.81 & 3.87 & 0.027 & 0.129 \\
\hline $\mathrm{PA} * \mathrm{M}$ & 2 & 2.78 & 52 & 5.13 & 0.54 & 0.584 & 0.020 \\
\hline $\mathrm{S} * \mathrm{M}$ & 2 & 7.22 & 52 & 4.83 & 1.49 & 0.233 & 0.054 \\
\hline
\end{tabular}


WITHOUT DIABETES

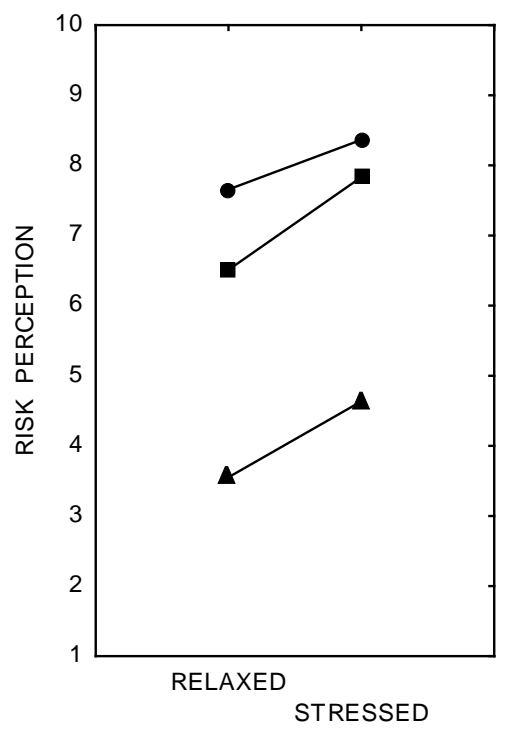

SEDENTARY

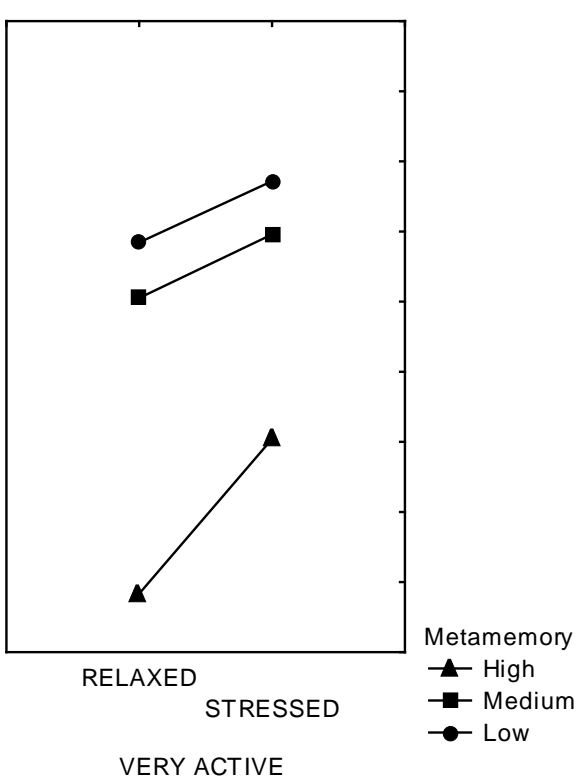

VERY ACTIVE



Figure 2. Interaction graph for metamemory, stress and physical activity for each group.

visual pattern seems to follow parallelism which points to a cognitive algebra summative model. Note that some older adults with diabetes apparently did not follow any cognitive algebraic behavior.

Generally speaking both groups agreed that the best possible scenario in the present study to health self-care is to be cognitive fitted, relaxed and doing exercise. Interestingly, physical activity as well as memory capacity is not as relevant to people with diabetes as it is to people without diabetes (Table 2). Furthermore, if any evidence can be found for systematic thinking underlying the best possible scenario then the group without diabetes' judgment is the one to be considered. Some considerations about these results are discussed next.

\section{Discussion}

Theories like reasoned action (TRA) and planned behavior (TPB) assume that people's behavior follows reasonably from their beliefs. However, "reasonable behavior" can take different connotations other than theoreti- 
cal assumptions. More than often, patients' judgments of the seriousness of diabetes are different from those of professionals [14]. For example, in this study people with diabetes psychologically valuated very low physical activity lower than nondiabeticts compared to cognitive or emotional factors. Is this reasonable? Rather, being cognitive fitted is most relevant to be able to take care of their health. Why? Well, no doubt this is desirable but tricky. For instance, overcompensating sugar based food intake by incrementing insulin requires cognitive control. Metamemory control over schedule medication is relevant to health since small portions or "food sins" would not constitute a health threat. Control over this health outcome might be diminished by declined memory capacity.

Most relevant to the diabetes group was that no clear well-defined systematic thinking pattern was observed (neither summative nor multiplicative) underlying judgment. However, the Fishbein-Ajzen's TPB/TRA approach assumes a summation of multiplicative believes values to attitude formation which in turn defines intention to behavior. This is not supported by the current study results when the case of older adults with diabetes is under scrutiny. No summation process was observed. This is a limitation of the Fishbein-Ajzen approach where the cognitive nature of beliefs cannot be explored.

The above does not imply that under clinical behavioral intervention this unsystematic cognitive judgment could not be changed. However, an IIT approach must be considered to achieve this goal. Specifically, valuation of factors where physical activity achieves better relevance must be a goal of behavioral intervention. This is indeed relevant but senseless if no cognitive ruled behavior accompanies this intervention goal. Accordingly, risk perception about health threatens should follow an implicit cognitive rule defined as:

$$
\mathrm{RP}=\text { Metamemory }_{\mathrm{Wm}_{\mathrm{m}}}+\text { Stress }_{\mathrm{ws}_{\mathrm{s}}}+\text { Physical Activity }_{\mathrm{Wpa}_{\mathrm{pa}}}
$$

where perceived risk (RP) results from orthogonal contributions of weighted $\left(\mathrm{W}_{\mathrm{ij}}\right)$ factor values. The possibility of successfully achieving this cognitive behavior on people with diabetes after behavioral intervention comes from simply considering that all equation parameters can be estimated for the group of people without diabetes.

At least two additional benefits can be acquired from an IIT approach. First, notice that another cognitive function underlying a belief can be explored by including new factors into RP (say self-concept or self-esteem) or by dropping factors from RP. Second, there is a possibility to induce different cognitive ruled models (multiplicative or average) on patients with diabetes after clinical intervention. More research is needed. It is evident that if more predictive behavior power is to be achieved then the relation of prediction models like the ones appointed before and the cognitive rules behavior of a belief need to be determined.

\section{References}

[1] Conner, M. and Norman, P. (2005) Predicting Health Behaviour: Research and Practice with Social Cognition Models. 2nd Edition, Open University Press, Maidenhead.

[2] McEachan, R.R.C., Conner, M., Taylor, N.J. and Lawton, R.J. (2011) Prospective Prediction of Health-Related Behaviors with the Theory of Planned Behavior: A Meta-Analysis. Health Psychology Review, 5, 97-144. http://dx.doi.org/10.1080/17437199.2010.521684

[3] Fishbein, M. (2008) A Reasoned Action Approach to Health Promotion. Medical Decision Making, 28, 834-844. http://dx.doi.org/10.1177/0272989X08326092

[4] Yzer, M. (2010) The Impact of the Work of Martin Fishbein on Health Issues in the World. Health Communication, 25, 625-627. http://dx.doi.org/10.1080/10410236.2010.496840

[5] Jaccard, J. and Becker, M.A. (1985) Attitudes and Behavior: An Information Integration Perspective. Journal of Experimental Social Psychology, 21, 440-465. http://dx.doi.org/10.1016/0022-1031(85)90029-0

[6] Jaccard, J., Radecki, C., Wilson, T. and Dittus, P. (1995) Methods for Identifying Consequential Beliefs: Implications for Understanding Attitude Strength. In: Pety, R.E. and Crosnik, J.A., Eds., Attitude Strength, Lawrence Erlbaum Associates, Mahwa, 337-359.

[7] Anderson, N.H. (2009) Unified Social Cognition. Psychology Press, New York.

[8] Ajzen, I. and Fishbein, M. (2005) The Influence of Attitudes on Behavior. In: Albarracín, D., Johnson, B.T. and Zanna, M.P., Eds., The Handbook of Attitudes, Erlbaum, Mahwah, 173-221.

[9] Abraham, C. and Sheeran, P. (2005) The Health Belief Model. In: Conner, M. and Norman, P., Eds., Predicting Health Behaviour: Research and Practice with Social Cognition Models, 2nd Edition, Open University Press, Maidenhead, 28-80.

[10] Harris, R., Skyler, J.S., Linn, M.W., Pollack, L. and Tewksbury, D. (1982) Relationship between the Health Belief 
Model and Compliance as a Basis for Intervention in Diabetes Mellitus. Pediatric and Adolescent Endocrinology, 10, 123-132.

[11] Anderson, N.H. (1991) Contributions to Information Integration Theory. Erlbaum, Hillsdale.

[12] Anderson, N.H. (1971) Integration Theory and Attitude Change. Psychological Review, 78, 171-206. http://dx.doi.org/10.1037/h0030834

[13] Mairese, O., Macharis, C., Lebeau, K. and Turcksin, L. (2012) Understanding the Attitude-Action Gap: Functional Integration of Environmental Aspects in Car Purchase Intentions. Psicológica, 33, 547-574.

[14] Clark, M. and Hampson, S.E. (2003) Comparison of Patients' and Healthcare Professionals' Beliefs about and Attitudes towards Type 2 Diabetes. Diabetic Medicine, 20, 152-154. http://dx.doi.org/10.1046/j.1464-5491.2003.00896.x

[15] Harvey, J.N. and Lawson, V.L. (2009) The Importance of Health Belief Models in Determining Self-Care Behavior in Diabetes. Diabetic Medicine, 26, 5-13. http://dx.doi.org/10.1111/j.1464-5491.2008.02628.x

[16] Harris, R., Skyler, J.S., Linn, M.W., Pollack, L. and Tewksbury, D. (1982) Relationship between the Health Belief Model and Compliance as a Basis for Intervention in Diabetes Mellitus. Pediatric and Adolescent Endocrinology, 10, 123132.

[17] Klein, H.A. and Meininger, A.R. (2004) Self-Management of Medication and Diabetes: Cognitive Control. IEEE Transactions on Systems, Man, and Cybernetics, Part A: Systems and Humans, 34, 718-725.

[18] Conner, M. (2010) Cognitive Determinants of Health Behavior. In: Steptoe, A., Ed., Handbook of Behavioral Medicine, Springer Verlag, New York.

[19] Lewis, K. (1994) An Examination of the Health Belief Model When Applied to Diabetes Mellitus. Unpublished Doctoral Thesis, Department of Psychology, University of Sheffield, Sheffield.

[20] van Harten, B., Oosterman, J., Muslimovic, D., van Loon, B.J., Scheltens, P. and Weinstein, H.C. (2007) Cognitive Impairment and MRI Correlates in the Elderly Patients with Type 2 Diabetes Mellitus. Age \& Aging, 36, 164-170. http://dx.doi.org/10.1093/ageing/afl180

[21] Wessels, A.M., Pouwer, P.H., Geelhoed, D.P.H.LM., Snel, M., Kostenset, P.J., Schelensens, P., Heine, R.J. and Snoek, F.J. (2007) No Evidence for Increased Self-Reported Cognitive Failure in Type 1 and 2 Diabetes: A Cross-Sectional Study. Diabetic Medicine, 24, 735-740. http://dx.doi.org/10.1111/j.1464-5491.2007.02153.x

[22] Allen, K.V., Frier, B.M. and Strachan, M.W. (2004) The Relationship between Type 2 Diabetes and Cognitive Dysfunction: Longitudinal Studies and Their Methodological Limitations. European Journal of Pharmacology, 490, 169175. http://dx.doi.org/10.1016/j.ejphar.2004.02.054

[23] Kumar, R., Looi, J.C.L. and Beverly, R. (2009) Type 2 Diabetes Mellitus, Cognition and Brain Aging: A Brief Review. Indian Journal Psychiatry, 51, 35-37.

[24] Umegaki, H., Iimuro, S., Shinozaki, T., Araki, A., Sakurai, T., Iijima, K., Ohashi, Y. and Ito, H. (2012) Risk Factors Associated with Cognitive Decline in the Elderly with Type 2 Diabetes: Baseline Data Analysis of the Japanese Elderly Diabetes Intervention Trial. Geriatrics \& Gerontology International, 12, 103-109. http://dx.doi.org/10.1111/j.1447-0594.2011.00817.x

[25] van Eersel, M.E.A., Joosten, H., Gansevoort, R.T., Dullaart, R.P.F., Slaets, J.P.J. and Gerbrand, J.I. (2013) The Interaction of Age and Type 2 Diabetes on Executive Function and Memory in Persons Aged 35 Years or Older. PLoS ONE, 8, 1-7. http://dx.doi.org/10.1371/journal.pone.0082991

[26] Hernández-Cortéz, P.L., Octavio, L.R.E., Martínes, M.G.E. and Salazar-Gonzáles, B.C. (2014) Automatic Information Processing Bias to Stress Factors by Old People with and without Diabetes. Advances in Aging Research, 3, $230-238$. http://dx.doi.org/10.4236/aar.2014.33032 
Scientific Research Publishing (SCIRP) is one of the largest Open Access journal publishers. It is currently publishing more than 200 open access, online, peer-reviewed journals covering a wide range of academic disciplines. SCIRP serves the worldwide academic communities and contributes to the progress and application of science with its publication.

Other selected journals from SCIRP are listed as below. Submit your manuscript to us via either submit@scirp.org or Online Submission Portal.
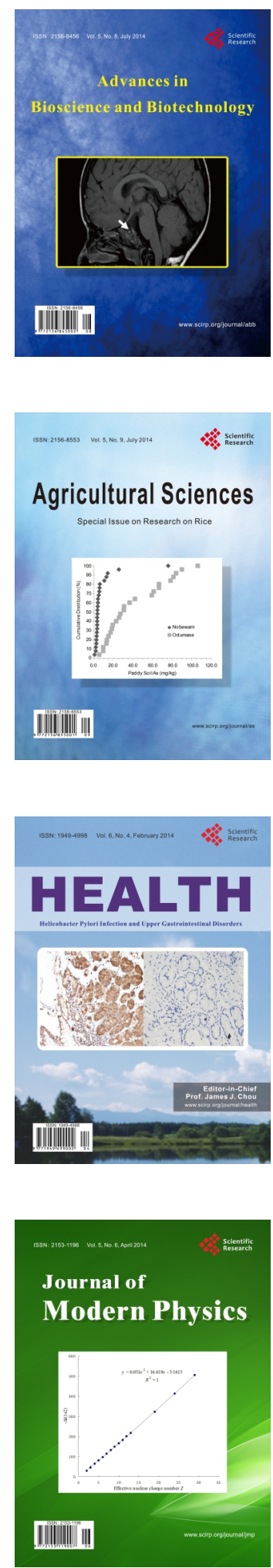
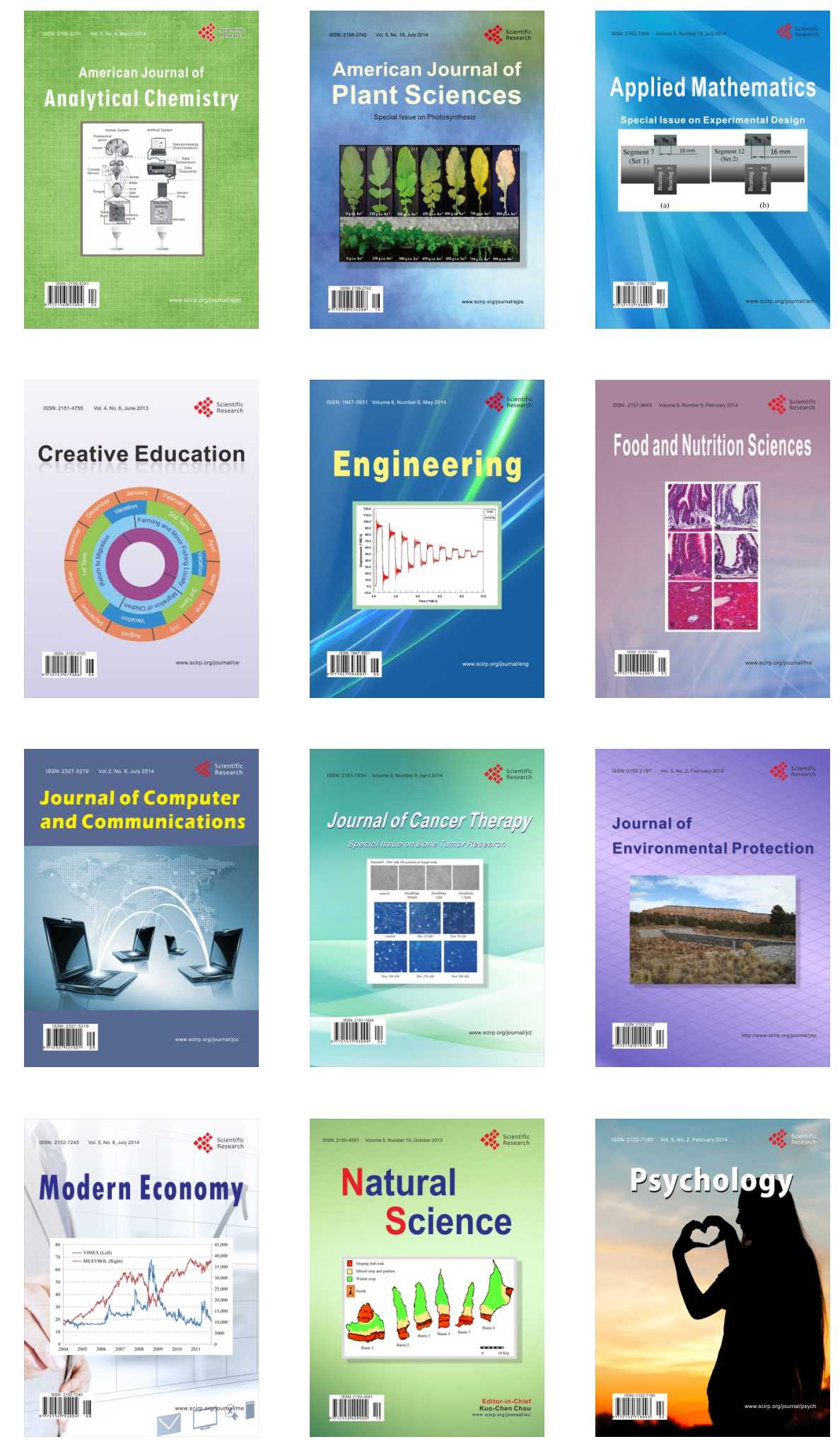